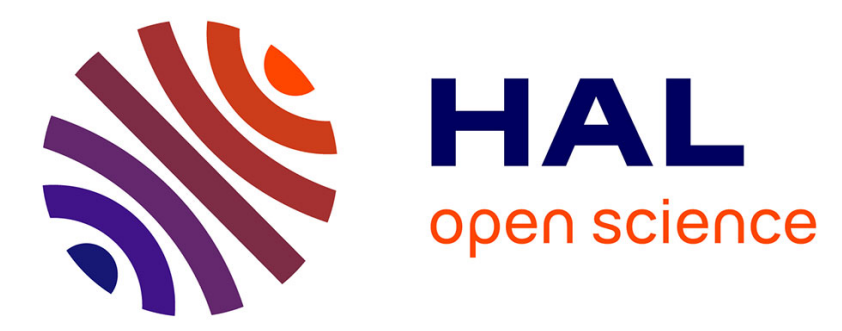

\title{
Soundscape of urban-tolerant crickets (Orthoptera: Gryllidae, Trigonidiidae) in a tropical Southeast Asia city, Singapore \\ Ming Kai Tan
}

\section{To cite this version:}

Ming Kai Tan. Soundscape of urban-tolerant crickets (Orthoptera: Gryllidae, Trigonidiidae) in a tropical Southeast Asia city, Singapore. 2020. hal-02946307

\section{HAL Id: hal-02946307 \\ https://hal.science/hal-02946307}

Preprint submitted on 23 Sep 2020

HAL is a multi-disciplinary open access archive for the deposit and dissemination of scientific research documents, whether they are published or not. The documents may come from teaching and research institutions in France or abroad, or from public or private research centers.
L'archive ouverte pluridisciplinaire HAL, est destinée au dépôt et à la diffusion de documents scientifiques de niveau recherche, publiés ou non, émanant des établissements d'enseignement et de recherche français ou étrangers, des laboratoires publics ou privés. 
1 Soundscape of urban-tolerant crickets (Orthoptera: Gryllidae, Trigonidiidae) in a

2 tropical Southeast Asia city, Singapore

3

$4 \quad$ Ming Kai Tan ${ }^{1}$

5

$6{ }^{1}$ Institut de Systématique, Evolution et Biodiversité (ISYEB), Muséum national d'Histoire

7 naturelle, CNRS, SU, EPHE, UA, 57 rue Cuvier, CP 50, 75231 Paris Cedex 05, France;

8 Email: orthoptera.mingkai@gmail.com

9

10

11 


\section{Abstract}

13

14 Urbanisation impact biodiversity tremendously, but a few species can still tolerate the harsh conditions of urban habitats. Studies regarding the impact of urbanisation on the soundscape and acoustic behaviours of sound-producing animals tend to overlook invertebrates, including the crickets. Almost nothing is known about their acoustic community in the urban environment, especially for Southeast Asia where rapid urbanisation is widespread. Grass verges in Singapore - characterised by complex mosaics of land-use types — were sampled as a microcosmic representation of the urban environment to address these questions: (i) What is the acoustic community of crickets in the urban environment? (ii) How do co-occurring species partition their calls? (iii) How do the call properties vary with environmental conditions and individuals? The calling songs of ten species were recorded and they generally have distinct call signatures in both the time and frequency domains. The acoustic community was dominated by Polionemobius taprobanensis and Gryllodes sigillatus. They also showed repeatabilites in their call properties with static properties being more repeatable than dynamic properties, but these call properties were not associated with environmental variables. The presence of these crickets is highly relevant for a biophilic city as they represent what most urban dwelling humans could frequently hear.

Key words: calling song, niche partitioning, noise pollution, repeatability, urbanisation

\section{Introduction}

Urbanisation represents an extreme form of environmental change and is a major driver of 
fraction of species can tolerate, exploit and persist in the novel environment created as a result of urbanisation (Newbold et al. 2015). Ability to communicate in the noisy urban soundscape - dominated by vehicular traffic, construction work among other human activities - is one of the few behavioural responses that help these species adapt to the novel environment.

The urban soundscape can have consequences on the wellbeing and quality of life for human city-dwellers, which accounts for more than half of global human populations (Stockfelt 1991; Raimbault and Dubois 2005). The study of urban soundscape since evolved from tackling noise pollution in urban areas to enhancing quality of the environment through improved urban development (Stockfelt 1991; Skanberg and Ohrstrom 2002). However, more recently, many city planners have attempted to make the cities more liveable by incorporating greeneries and improving soundscape (Irvine et al. 2009).

Likewise, anthropogenic noises also have effect on the animals in the city. One of the most distinct natural sounds that can still be present in an urban city belongs to that of birds. Studies of avian acoustic ecology in urban context have drawn huge attention, including on how birds adapt their calling patterns to urban noises (e.g., Hu and Cardoso 2010; Nemeth and Brumm 2010; Slabbekoorn 2013; Gil and Brumm 2014). Likewise, bats use ultrasonic sounds to navigate and search for prey; and their activities and behaviours are also greatly altered in the urban environments compared to counterparts in the forest (Gehrt and Chelsvig 2004; Smith and Gehrt 2010; Coleman and Barclay 2012). Such urban studies are primarily focusing on vertebrates while overlooking the invertebrates. 
61 One of the most notable sound-producing invertebrates is the crickets and their relatives. Many crickets and bush-crickets rub their forewings to produce sound during which the teeth of the stridulatory file on the left tegmen contact the scraper on the right tegmen (Elliot and Koch 1985; Bennet-Clark 1989). While bush-crickets of the superfamily Tettigonioidea with known calls generally produce ultrasonic songs (Montealegre-Z et al. 2006), crickets of the superfamily Grylloidea typically produce pure-tone calls that are audible to human (Otte 1992). In contrast to birds and bats, relatively little is known about the orthopteran acoustics in urban areas, even though calls made by male orthopterans are one of the most dominant sounds in the natural habitats.

A main reason for the gap on the orthopteran acoustics in urban context is that very few orthopterans can survive the harsh environment of urban city landscape. The most wellknown urban-tolerant species are probably the Gryllodes sigillatus (Walker, 1869) and Acheta domesticus (Linnaeus, 1758) from the tropics and temperate respectively. At present, these species have established in urban ecosystems in many parts of the world (Weissman and Rentz 1977; Smith and Thomas 1988), but it is less clear what other species can also adapt to the urban environment. Therefore, the first objective of this study is to investigate what species can be heard in an urban habitat.

Urban cricket populations can have different requirements as populations found in their natural habitats (Fartmann et al. 2008). For example, higher temperature owing to urban island heat effects can change voltinism in nemobines (Matsuda et al. 2018) as well as their calling properties (Walker, 1962; Bennet-Clark 1989; Martin et al. 2000). In addition to environmental-driven effects on cricket acoustics, urban crickets need to compete for acoustic space (both frequency and temporal domains) with males of the same and different species to 
attract conspecific mates. It was previously demonstrated that presence of anthropogenic sound leads to increased pauses between calling and call durations (Orci et al. 2016; Duarte et al. 2019), increased amplitude of calls (which may make them more vulnerable to predation) (Erregger and Schmidt 2018) and increased difficulty for females to locate calling males (Bent et al. 2018; Gurule-Small and Tinghitella 2018). These selection pressures can also drive between- and within-individual variations that differ from that among individuals from the natural habitats. As such, the second objective of this study is to further investigate how the call properties of the urban-tolerant species vary and/or partition between different individuals, species and environmental conditions.

Studies on urban-tolerant crickets typically originate in temperate or New World tropics (e.g., Orci et al. 2016; Bent et al. 2018; Duarte et al. 2019). There remains a dearth of information about orthopteran bioacoustics in tropical Asia, including Singapore situated in the biodiverse tropical Southeast Asia. Singapore is a highly urbanised, built-up and densely populated island city-state (Newman 2014). Self-proclaimed as a "City in a Garden”, Singapore has invested greatly on the streetscape management to create a 'seamless green mantle' throughout the island (Newman 2014). This creates microhabitats along grass verges that some urban-tolerant orthopterans can potentially thrive in.

Research on the orthopterans from Singapore has caught up in the past decade, particularly on species diversity (e.g., Tan 2010, 2012, 2013), new species discovery (e.g., Gorochov and Tan 2012; Tan and Robillard 2014), ecology (e.g., Tan and Tan 2017; Tan et al. 2017a) and natural history (e.g., Tan 2011; Tan et al. 2017b, Fung et al. 2018). As many as 200 species of orthopterans can be found in the forest remnants of Singapore but studies incorporating bioacoustics data is relatively few (but see Gorochov and Tan 2012; Tan and Robillard 2014) 
and concerted investigation on the orthopteran calls from Singapore is scanty (but see Tan et al. 2018, 2019). Furthermore, most of these studies were done in the forested and natural environment rather than the highly urbanised parts of Singapore (but see Tan 2010, 2012).

114 Nonetheless, these ample resources have provided an important basis to facilitate urban 115 studies.

117 In summary, the current gap on the urban species and acoustics of crickets in Singapore 118 prompted me to address the following questions: (i) What is the acoustic community of 119 crickets in the urban environment of Singapore? (ii) How do co-occurring urban-tolerant species partition their calls from each other? (iii) How do the call properties of the urbantolerant species vary between environmental conditions and individuals?

\section{Materials and Methods}

Study area

I sampled the grass verges (approximately $5 \mathrm{~m}$ in width) bordering road and walkways around Kampong Ubi (N1.32857, E103.90238) (Singapore)—specifically along Ubi Avenue 1, Ubi Road 3 and Ubi Avenue 2 (Fig. 1). The area within which the roads encircle comprises of two schools (Maha Bodhi School and Manjusri Secondary School), a Mass Rapid Transit train station (Ubi DT27) and a construction site for an upcoming housing estate. The grass verges are surrounded by dense public housing along Ubi Avenue 1 and light industry along Ubi Road 3 and Ubi Avenue 2. These make this study area a microcosmic representation of 134 the urbanised environment of Singapore which is characterised by complex mosaics of landuse types. 
137 I sampled over seven nights between 18 and 30 May 2020, commencing at around 2000

138 hours for an average of 1 hour. This involved walking along the walkways and

139 opportunistically recording songs of crickets in situ whenever they were encountered. I

140 obtained from the Meteorological Service Singapore (MSS) (Meteorological Service

141 Singapore undated) the daily temperature and rainfall data from the nearest weather station

142 (i.e., Tai Seng, N1.3399, E103.8878, about $1.9 \mathrm{~km}$ from study site).

143

\section{Recording of calls}

145 I recorded the male calls using a portable ultrasound recorder Echo Meter Touch Pro 2

146 (Wildlife Acoustics, Inc. USA, Massachusetts), attached to a Samsung smart phone, and 147 using a sampling frequency of $256 \mathrm{kHz}$-samples/s. The Echo Meter Touch Pro 2 (based on

148 Knowles FG sensor, 16-bit WAV, mono channel, with frequency response of up to $128 \mathrm{kHz}$ )

149 was placed as close as possible to the cricket without disturbing the cricket, and to maximise

150 amplitude without clipping the sound. Manual trigger was used. As temperature can influence

151 the song parameters, a HOBO 8K Pendant ${ }^{\circledR}$ Temperature logger (model: UA-001-08, Onset,

152 Bourne, MA) was used to track the ambient temperature once every 10 minutes. The GPS

153 coordinates were also obtained using Google Earth Pro (Google Earth Pro 2020) so that

154 recordings in the subsequent sampling nights were far apart enough to minimise the

155 probability "double-counting" of the same cricket individual. Male crickets which were

156 recorded are generally territorial and do not travel away from their burrow or territory during

157 calling. Selected sound files were uploaded to the Orthoptera Species File Online Version

158 5.0/5.0 (OSF) (Cigliano et al. 2020).

159

160 Species examination and identification 
161 Whenever possible, I collected the singing crickets for vouchering. The male genitalia were

162

163

164

165

166

167

168

169

170

171

172

173

174

175

176

177

178

179

180

181

182

183

184

185

dissected under stereo-zoom microscope, examined and the species were identified using taxonomic papers (Gorochov 1983; Otte 2006). When no specimen was available, I used Tan $(2011,2012,2017)$ to narrow down possible candidate species that can occur in the grass verges and compared the calls with existing sound files deposited in the OSF and unpublished sound files of calls by Singaporean crickets.

\section{Acoustic analyses}

The basic cricket song terminology follows Ragge and Reynolds (1998). Calling song is the spontaneous song produced by an isolated male. One song unit is called a syllable and corresponds to one opening-closure cycle of the male forewings. A group of syllables constitutes an echeme, which corresponds to a call unit in terms of communication. I measured the call duration and syllable duration manually using Avisoft Lite 2.0.0. Power spectra using Fast Fourier Transformation (FFT) were generated using the 'meanspec' function at 256,000 sampling frequency, using Hanning window of window length 512 from the R package seewave (Sueur et al. 2008) in the R software version 3.5.1 (R Development Core Team, 2018). Dominant frequency (frequency with the highest energy), second dominant frequency and fundamental frequency (lowest frequency of a harmonic series) were determined from the power spectra.

\section{Statistical analyses}

All statistical analyses were conducted with R version 3.5.1 (R Development Core Team 2018). To obtain an indication of sample adequacy, I plotted an individual-based species rarefaction curve using the 'specaccum' function from the $\mathrm{R}$ package vegan (Oksanen et al. 2015). 
187 To examine how co-occurring urban species partition their calls from each other, I

188 summarised the call properties (which were not mutually independent and likely to be highly

189 intercorrelated) into major gradients of variation by performing a Principal Coordinates

190 Analysis (PCoA) on the scaled call properties using the 'cmdscale' function. Gower

191 dissimilarity was used as it can be calculated for a set of descriptors containing of continuous

192 (bounded by zero) (i.e., echeme duration, syllable duration, dominant frequency, second

193 dominant frequency, fundamental frequency) and categorical variables (i.e., call types-

194 continuous trills or echemes consisting of a few syllables).

196 To investigate how the call properties of the urban-dwelling crickets correlate with

197 environmental variables, I fitted univariate linear mixed effects models (LMMs) for

198 fundamental frequency and syllable duration using the 'lmer' function from the R package

199 lme4 (Bates et al. 2014). I log-transformed both response variables. The ambient temperature

200 at the time of recording $\left({ }^{\circ} \mathrm{C}\right)$, mean daily temperature $\left({ }^{\circ} \mathrm{C}\right)$ and daily rainfall total $(\mathrm{mm})$

201 obtained from (MSS) were fitted as fixed effects. I checked for collinearity between the fixed

202 effects, and all fixed effects were centred on their means to facilitate model fitting. Since I used multiple calls for each individual cricket, the 'cricket identity' was fitted as a random intercept. I fitted seven models containing different plausible combinations of the fixed

205 effects as well as a null model without any fixed effect. The models were compared using

206 AICc, which estimates the quality of each model by rewarding goodness of fit and penalizing 207 overfitting (Burnham and Anderson 2002). Models with the differences between the values of 208 the AICc of a particular model and that of the best model (delta) less than 2.0 (Burnham and 209 Anderson 2002) were considered equally good and thus interpreted together. I used the 210 Akaike weight of each model (which translates to the probability that the model is the best 
211 model) and the marginal and conditional $\mathrm{R}^{2}$ values (i.e., $\mathrm{R}_{\mathrm{M}}^{2}$ and $\mathrm{R}_{\mathrm{C}}^{2}$, respectively) obtained

212 using the 'r.squaredGLMM' function in the R package MuMIn (Barton and Barton 2015) to 213 assess the quality of the models.

214

215 To assess repeatability of the call properties, I followed the mixed effect modelling approach

216 by Nakagawa and Schielzeth (2010) and Dingemanse and Dochtermann (2013). Repeatability

217 here is defined as the intraclass correlation coefficient (ICC), which is calculated as the ratio

218 of inter- individual cricket variance and the sum of inter- and within-individual cricket

219 variance (Nakagawa and Schielzeth, 2010). To calculate ICC after controlling for variation

220 due to covariates, I used the functions 'rpt' function from the R package $r p t R$ (Stoffel et al.

221 2017) for fundamental frequency and syllable duration with the fixed and random effects

222 specified based on the final model after model selection by AICc described above.

223 Repeatability estimates larger than 0.1 were considered as weak evidence, even if the

224 estimated CI included zero; and repeatability estimates smaller than 0.1 as not repeatable,

225 even if the p-value suggested significance (Schuster et al. 2017).

226

227

228

229

230

231

232

233

234

\section{Results}

\section{(i) What is the acoustic community of crickets?}

I recorded the calls of 42 individuals from ten species of crickets and bush-cricket (Fig. 2,

Table 1). These include five species from Gryllidae and four species from Trigonidiidae; and one species from Tettigoniidae. 
235 The most commonly heard gryllid is the Gryllodes sigillatus (Walker, 1869) [Gryllidae:

236 Gryllinae]. Commonly known as the decorated cricket, they can be heard calling in both

237 vegetated and non-vegetated structures, including drains, and concrete crevices. The male call 238 (echeme duration $=55.6 \pm 5.8 \mathrm{~ms}[45.6-68.2 \mathrm{~ms}]$ ) consists of echemes with four syllables of 239 increasing amplitudes and duration (Fig. 3a), and has a harmonic series with the dominant 240 frequency $(=7.3 \pm 0.4 \mathrm{kHz}[6.5-8.0 \mathrm{kHz}])$ typically peaking in the first harmonic (also the 241 fundamental frequency) (Fig. 4a). The echemes are closely and more or less consistently 242 spaced apart (Fig. 3a).

243

244 Gryllus bimaculatus De Geer, 1773 [Gryllidae: Gryllinae] call (echeme duration = $2450.205 \pm 0.039 \mathrm{~s}[0.145-0.265 \mathrm{~s}]$ ) consists of echemes with four to five syllables (Fig. 3b), and 246 has a harmonic series with a fundamental frequency of $4.5 \mathrm{kHz}$ and a dominant frequency of

$24713.1 \pm 0.2 \mathrm{kHz}[13.0-13.5 \mathrm{kHz}]$ (Fig. 4b). The echemes are more widely spaced apart and 248 down times are less consistent (Fig. 3b). I did not encounter the cricket but was able to 249 identify the calls using sound file uploaded in OSF [SoundID = 1295].

250

Teleogryllus c.f. mitratus (Burmeister, 1838) [Gryllidae: Gryllinae] call is loud and distinct 252 from other gryllids, consisting of a relatively long trill (echeme duration $=1.05 \pm 0.05 \mathrm{~s}[0.97-$

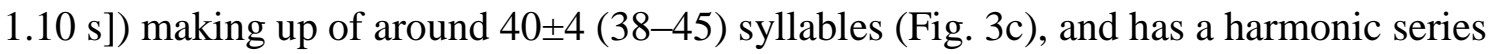

254 with the dominant frequency $(=11.6 \pm 1.6 \mathrm{kHz}[10.0-13.0 \mathrm{kHz}])$ peaking in the second 255 harmonic; and fundamental frequency of $3.5 \mathrm{kHz}$ (Fig. 4c). I also did not encounter the cricket but identified the calls using unpublished sound files and sound file uploaded in OSF

$257 \quad($ SoundID $=1756,1759)$. 
259 An unknown species of Gryllinae can be heard fairly frequently, albeit not as frequent as $G$. 260 sigillatus, and often a few individuals call in close proximity to each other. The call consists 261 typically of syllables occurring in doublets (echeme duration $=71.3 \pm 6.5 \mathrm{~ms}$ [63.9-93.9 $\mathrm{ms}$; 262 syllable duration $=30.3 \pm 3.8 \mathrm{~s}[26.0-45.0 \mathrm{~ms}])($ Fig. $3 \mathrm{~d})$, and has a harmonic series with the 263 dominant frequency either peaking in the first harmonic (i.e., = fundamental frequency of 5.5 $264 \mathrm{kHz}$ ) or peaking in the third harmonic of $17 \mathrm{kHz}(16.5-17.5 \mathrm{kHz})($ Fig. 4d). The second 265 harmonic peaks at $11.5 \mathrm{kHz}$. The calls are drastically different from that of Velarifictorus aspersus (Walker, 1869) which is a common gryllid in Singapore but not recorded in this study.

268

269 I tentatively identified the calls of this single specimen as Mitius sp. [Gryllidae: Gryllinae] 270 based on the calls of Mitius blennus (Saussure, 1877) and Mitius enatus Gorochov, 1994 from OSF (SoundID $=1792,1794$, respectively), of which they are somewhat similar in the dominant frequency and syllable duration. The male call (echeme duration $=69.4 \pm 1.6 \mathrm{~ms}$ $[67.1-71.0 \mathrm{~ms}])$ consists of echemes with four syllables $($ syllable duration $=12.3 \pm 1.1 \mathrm{~ms}$ [11.4-13.8 ms]) (Fig. 3e), and has a harmonic series with the dominant frequency $(=9.5 \mathrm{kHz})$ peaking in the first harmonic (also the fundamental frequency) (Fig. 4e).

276

277

Polionemobius taprobanensis (Walker, 1869) [Trigonidiidae: Nemobiinae] is the most

278 frequently recorded cricket. Males call both in the day and at night. Calling males were never 279 encountered, as they appear to hide among leaf blades and sheaths of grasses. The males' call 280 is a continuous trill of infinite number of syllables (syllable duration $=5.7 \pm 0.9 \mathrm{~ms}[3.6-7.8$ $\mathrm{ms}$ ) (Fig. 3f), comprising of a harmonic series with the dominant frequency $(=10.8 \pm 0.7 \mathrm{kHz}$ [7.0-12.0 kHz]) peaking in the first harmonic (= fundamental frequency) (Fig. 4f). 
284 Pteronemobius sp. [Trigonidiidae: Nemobiinae] has very similar niche and calls as $P$.

285 taprobanensis. The male's call differs by echeme consisting of a short trill (echeme duration $286=0.84 \pm 0.11 \mathrm{~s}[0.52-0.99 \mathrm{~s}])$ with around $110 \pm 17(81-150)$ syllables per echeme (syllable 287 duration $=7.6 \pm 0.6 \mathrm{~ms}[6.4-8.9 \mathrm{~ms}])($ Fig. $3 \mathrm{~g})$. Each syllable increases in amplitude within 288 each echeme (Fig. 3g). The call comprises of a harmonic series with the dominant frequency $289(=9.8 \pm 0.3 \mathrm{kHz}[9.5-10.0 \mathrm{kHz}])$ peaking in the first harmonic (= fundamental frequency) (Fig. 290 $4 \mathrm{~g})$.

Another distinct but unidentified species of Nemobiinae (owing to the lack of specimen) has call consisting of trills with varying duration (echeme duration $=0.12 \pm 0.02 \mathrm{~s}[0.08-0.14 \mathrm{~s}]$ ) with around $13 \pm 3(7-17)$ syllables per echeme (syllable duration $=9.3 \pm 0.8 \mathrm{~ms}[8.5-10.1 \mathrm{~ms}]$ ) (Fig. 3h). The call comprises of a harmonic series with the dominant frequency $(=6.5 \mathrm{kHz})$ peaking in the first harmonic (= fundamental frequency) (Fig. 4h).

A single unidentified Trigonidiinae was also recorded. The specimen was not collected successfully. The male's call consists of continuous trills of infinite number of syllables $($ syllable duration $=31.4 \pm 2.2 \mathrm{~ms}[27.9-34.9 \mathrm{~ms}])($ Fig. 3i), comprising of a harmonic series with the dominant frequency $(=8.0 \pm 0.3 \mathrm{kHz}[7.5-9.0 \mathrm{kHz}])$ peaking generally in the first harmonic (= fundamental frequency) (Fig. 4i). Compared to P. taprobanensis, the down time between syllables are also longer (Fig. 3i). The trigoniid was sighted, somewhat unicolorous pale yellow and resembling Natula longipennis (Serville, 1838) but differs in the call properties.

307 The only bush-cricket recorded was that of a Euconocephalus sp. (sensu Tan, 2011)

308 [Tettigoniidae: Conocephalinae]. This bush-cricket could only be heard among taller grasses 
and sedges when the grass verges were left unmanaged for considerable period. The call consists of a broad-band continuous trill of infinite number of syllables (syllable duration $=$ $2.72 \pm 0.22 \mathrm{~ms}[2.25-3.10 \mathrm{~ms}])$ (Fig. $3 \mathrm{j})$ with dominant frequency $(11.8 \pm 0.6 \mathrm{kHz}[11.0-13.5$ $\mathrm{kHz}]$ ) and another near-ultrasonic peak at 20.7 $\pm 0.9 \mathrm{kHz}(18.5-22.5 \mathrm{kHz})$ (Fig. 4j).

\section{(ii) How do co-occurring urban-tolerant species partition their calls from each other?}

By summarising echeme duration, syllable duration, dominant frequency, second dominant frequency, fundamental frequency and call types (continuous trills or echemes consisting of a few syllables), the first two axes of the PCoA explained about $85.2 \%(73.6+11.5 \%)$ and showed that the calls of ten urban-tolerant species generally partition across both time and frequency domains (Fig. 5). This can be evident from the non-overlapping ellipses and data points between species. There are however two exceptions. The call of Euconocephalus sp. is very similar to that of $P$. taprobanensis based on the call properties, as shown by the overlapping ellipses in the PCoA plot (Fig. 5), but P. taprobanensis is more tonal with a distinct harmonic series whereas Euconocephalus sp. is more broadband (Fig. 4). The PCoA also suggests that the call properties of G. sigillatus and Nemobiinae sp. are very similar (Fig. 5) but examination of the oscillograms (Fig. 3) and power spectra (Fig. 4) reveal clear-cut differences.

\section{(iii) How do the call properties of the urban-tolerant species vary between environmental}

\section{conditions and individuals?}

The model with delta $<2.0$ were found to be the null models for both $P$. taprobanensis $(\mathrm{n}=$ 169, 20 individuals) and $G$. sigillatus $(\mathrm{n}=64$ echemes, nine individuals) and for both syllable duration and fundamental frequency. These indicate that ambient temperature, mean daily 
temperature and daily rainfall total did not correlate strongly with both syllable duration and fundamental frequency (Table 2).

335

I found that syllable duration showed high repeatabilities, thus indicating consistent inter-

337 individual differences in both $P$. taprobanensis $(\mathrm{ICC}=0.45 \pm 0.10, \mathrm{p}$-value $<0.001,95 \% \mathrm{CI}$

$338[0.24,0.62])$ and $G$. sigillatus $(\mathrm{ICC}=0.59 \pm 0.15, \mathrm{p}$-value $<0.001,95 \% \mathrm{CI}[0.23,0.78])$. The

339

340

341

342

343

344

345

346

347

348

349

350

351

352

353

354

355

356

357

same is also observed for fundamental frequency in both $P$. taprobanensis $(\mathrm{ICC}=0.97 \pm 0.01$, p-value $<0.001,95 \%$ CI $[0.93,0.98])$ and $G$. sigillatus $(\mathrm{ICC}=0.96 \pm 0.03$, p-value $<0.001$, $95 \%$ CI $[0.85,0.98])$.

\section{Discussion}

\section{(i) What is the acoustic community of crickets?}

The acoustic community of crickets in the urban environment differs vastly from that of the forested or grassy habitats in Singapore. The acoustic community is dominated by the calls of P. taprobanensis and G. sigillatus. Gryllodes sigillatus is the most frequently heard gryllids in the urban environment but has not been recently encountered in Singapore's natural habitats. In contrast, other gryllids which are typically forest-edge or grassland species are only sparsely heard (Tan, 2017). Moreover, the acoustic community in the urban environment is limited to calls peaking at non-ultrasonic to near-ultrasonic frequencies ranging from 5.5 to $23.5 \mathrm{kHz}$, while the forests harbour more species which calls at ultrasonic frequencies (Tan et al. 2019). This suggests that the harsh urban conditions can only permit a very limited groups of crickets to exist. 
358 Numerous factors favour these urban-tolerant species to establish in the highly isolated grass verges (Møller 2009). Firstly, these often-flightless crickets need to be able to disperse into the urban areas which are isolated from natural habitats by road networks and human constructs. It is very likely that many of these species are transported through the grasses and

362 soil by human. Small species like P. taprobanensis and other nemobine lawn crickets can

363 hitch-hike among the grasses occasionally brought in by human to replenish the exposed surfaces. Other species, especially the less frequently encountered gryllids, may have been brought in through the soil where the eggs are laid along with the grasses. This begs the question whether how sustainable these cricket populations are, since nothing is known about their population dynamics and the dependence on new propagules in these grass verges, and that I did not encountered females of many species during the survey.

Secondly, low threshold for fear to human and anthropogenic noises is crucial for the males to continuing calling in the highly disturbed environment and for the females to be bold enough to travel and search for mates (Møller 2009; Lowry et al. 2011; Gallego-Abenza et al. 2019). This appears to be the case for most species recorded here, as noises generated by passing vehicles did not stop or modify the calling of many species. It is plausible that these crickets are already habituated to the anthropogenic noises (Bejder et al. 2009), a phenomenon which is also observed in some urban birds (e.g., Lowry et al. 2011; Payne et al. 377 2012).

379 Thirdly, the ability to utilise non-natural microhabitats and adapt to periodic human-induced microhabitat changes favours the establishment of species in urban areas. The greater

381 presence of impervious surfaces can limit gryllids to make burrows but G. sigillatus are 382 observed to exploit crevices of hard structures. I also observed that after the grass verges 
were mowed, $P$. taprobanensis continued calling on the same day and nearly as frequently as before the mowing occurred. This in turn can be attributed to the bolder nature of these urban-tolerant nemobines.

That other potential factors which can buffer individuals against the risks associated with an urban life, such as the tolerance to pesticide (from fogging of mosquito and cockroach) and toxic fumes from vehicles and constructions, are not known indicates that much remains unstudied about these urban-tolerant crickets and how urbanisation affects their behaviours (including acoustics). Rapidly expanding urbanisation in many other parts of Southeast Asia warrants the urgency of such studies to apprehend holistically the effect of urbanisation on wildlife and that invertebrates should receive more attention owing to their higher potential to respond to urban noises (Morley et al. 2015).

The rarefaction curve revealed that the sampling may be incomplete. But this may also be an artefact of the vegetation succession that occurred over the course of this study, leading to the colonisation of more species. For example, Euconocephalus sp. was recorded only towards the end of the study when the grasses grew taller and weeds flourished; and these katydids are known to prefer tall grasses over lawns (Tan 2011). However, such succession is atypical of Singapore's urban environment, if not for the Covid-19 pandemic during which grass mowing was halted during the national lockdown (Asher 2020; Hicks 2020). Increased in activity, acoustic diversity and complexity owing to vegetation succession have been reported in birds and insects (Fischer et al. 1997; Gasc et al. 2018; Wilson and Bayne 2019), but a future study on how the acoustic community of crickets respond to disturbances and successions may reveal interesting insights unique to urban environment. 
409 It was clear that the co-occurring urban-tolerant species partition their calls from each other,

410 as predicted, since the partitioning of call properties between closely related sympatric

411 species is crucial for reproductive isolation (Tan et al. 2018, 2019). The distinct differences in

412 both the frequency and time domains of the call properties (even within closely related

413 crickets) reduce interspecific acoustic competition (Sueur 2002; Chek et al. 2003), especially

414 since these crickets must also compete with anthropogenic noises (e.g., vehicles and

415 construction) in addition to singing hetero- and conspecific males.

417 However, I did not observe clear-cut temporal partitioning among the urban-tolerant crickets,

418 although Teleogryllus were generally heard towards the later hour of the surveys. This is

419 unlike the Gryllotalpa in Singapore's forest, where Gryllotalpa fulvipes Saussure, 1877

420 would call at around $6.30 \mathrm{pm}$ followed by Gryllotalpa nymphicus Tan, 2012 at around 7.00

421 pm (Tan 2017). This may be because unlike the Gryllotalpa, the call properties of the urban-

422 tolerant crickets are already sufficiently different. Furthermore, much fewer species occurring

423 in the grass verges perhaps also reduce the need to segregate their calling times and that

424 competition with constant anthropogenic noises may drive these crickets to call more

425 consistently throughout the night to maximise detection by conspecific females.

427 (iii) How do the call properties of the urban-tolerant species vary between environmental $428 \quad$ conditions and individuals?

429 Consistent inter-individual differences in the call properties signifies that some individuals 430 consistently call at higher fundamental frequency and with longer syllable duration than other individuals, thus implying a form of partitioning between conspecific individuals.

432 Repeatability in the call properties has been reported in a few crickets, including 
434 Nandi and Balakrishnan 2013), but not in other species (see Deb et al. 2012). I also found that 435 repeatabilities for fundamental frequency are higher than for syllable duration in both $P$. taprobanensis and G. sigillatus. This is in line with the current literature in which static

437 properties (including fundamental frequency) tend to exhibit higher repeatability than 438 dynamic properties (such as syllable duration) (Gerhardt 1991; Nandi and Balakrishnan 439 2013).

Such consistent inter-individual differences can be attributed to the environment and/or the

442 male conditions, which in turns have consequences on the mating success of the males

443 (Nandi and Balakrishnan 2013). Body size, which can be indicative of the age, fecundity and

444 fitness, is also known to correlate with call properties in some but not crickets (e.g., $G$.

445 sigillatus and G. bimaculatus) (Simmons and Zuk 1992; Champagnon and Castillo 2008). As

446 it was nearly impossible to collect the calling crickets, how the call properties are associated

447 with body size could not be examined here. Trigonids tend to hide among leave sheath of

448 grasses, whereas many gryllids quickly retreat into their burrows or crevices when their 449 surrounding grasses were disturbed.

450

451 However, there was no evidence from this study that temperature or rainfall are associated

452 with the static and dynamic call properties of both $P$. taprobanensis and G. sigillatus. This is 453 contrary to my prediction and previous studies, in which temperature affects most aspects of 454 calling songs, including syllable duration and frequency in other crickets (e.g., Walker, 1962;

455 Martin et al. 2000). Temperature influences the speed at which the cricket open and close its 456 wings, which directly affects the syllable duration and rate. Additionally, increased wing 457 closure also imply a faster passage of scraper across the teeth on the stridulatory file, thus 
leading to an increased frequency (Walker, 1962), although this is also not necessarily true 459 for all crickets (Bennet-Clark 1989).

460

461

\section{Conclusions}

462 Urban animals can have a potentially disproportionate impact on the health and well-being of 463 city-dwelling human beings (Newbold et al. 2015). As a "City in a Garden", the calls of 464 crickets at night should be an indispensable part of the overall natural soundscape in the 465 urban Singapore landscape. This study also demonstrates that the very few urban-tolerant 466 species may represent what most people would frequently hear. This is particularly relevant 467 since the crickets call among grass verges along walkways frequented by students from 468 schools, workers from the light industry and people from the surrounding housing 469 neighbourhood.

470

471

472 Acknowledgements

473

474 MK Tan thanks Huiqing Yeo for field assistance. The work of MK Tan is supported by the 475 Wildlife Reserves Singapore Conservation Fund (WRSCF). The acoustic recording 476 equipment was provided under the Wildlife Acoustics Scientific Product Grant 2019 under 477 the project titled "Discovery of Ultrasonic Singing Katydids in Southeast Asia".

\section{References}

481 
Asher S. 2020. Coronavirus in Singapore: The garden city learning to love the wild. BBC

Barton K, Barton MK. 2015. Package 'MuMIn’ Version 1.

Bates D, Maechler M, Bolker B, Walker S, Christensen RHB, Singmann H, Dai B. 2014. lme4: linear mixed-effects models using Eigen and S4 (Version 1.1-7).

Bejder L, Samuels A, Whitehead H, Finn H, Allen S. 2009. Impact assessment research: use and misuse of habituation, sensitisation and tolerance in describing wildlife responses to anthropogenic stimuli. Marine Ecology Progress Series. 395:177-185.

Bennet-Clark HC. 1989. Songs and the physics of sound production. In: Huber F, Moore TE, Loher W (eds.) Cricket Behaviour and Neurobiology, pp. 227-261. Ithaca: Cornell University Press.

493

Bent AM, Ings TC, Mowles SL. 2018. Anthropogenic noise disrupts mate searching in Gryllus bimaculatus. Behavioral Ecology. 29(6):1271-1277.

Burnham KP, Anderson DR. 2002, Model selection and multi-model inference: a practical information-theoretic approach. Springer, New York. 488 pp.

Champagnon J, Cueva del Castillo R. 2008. Female mate choice, calling song and genetic variance in the cricket, Gryllodes sigillatus. Ethology. 114(3):223-230.

Chek AA, Bogart JP, Lougheed SC. 2003. Mating signal partitioning in multi-species assemblages: a null model test using frogs. Ecology Letters. 6:235-247.

501 Cigliano MM, Braun H, Eades DC, Otte D. 2020. Orthoptera Species File online. Version 5 502 (5.0). Available from: http://orthoptera.speciesfile.org/HomePage/Orthoptera/HomePage.aspx (accessed 30 May 2020)

505 Coleman JL, Barclay RM. 2012. Urbanisation and the abundance and diversity of Prairie bats. 506 Urban Ecosystems. 15(1): 87-102. 
Deb R, Bhattacharya M, Balakrishnan R. 2012. Females of a tree cricket prefer larger males but not the lower frequency male calls that indicate large body size. Animal Behaviour. 84(1):137-149.

510 Dingemanse NJ, Dochtermann NA. 2013. Quantifying individual variation in behaviour:

511 mixed-effect modelling approaches. Journal of Animal Ecology. 82(1):39-54.

512 Duarte MH, Caliari EP, Scarpelli MD, Lobregat GO, Young RJ, Sousa-Lima RS. 2019.

513 Effects of mining truck traffic on cricket calling activity. The Journal of the Acoustical $514 \quad$ Society of America. 146(1):656-664.

515 Elliott CJH, Koch UT. 1985. The clockwork cricket. Naturwissenschaften. 72(3):150-153.

516 Erregger B, Schmidt AK. 2018. Anthropogenic calling sites boost the sound amplitude of 517 advertisement calls produced by a tropical cricket. Animal Behaviour. 142:31-38.

518 Fartmann T, Behrens M, Loritz H. 2008. Orthopteran communities in the conifer-broadleaved 519 woodland zone of the Russian Far East. European Journal of Entomology. 105(4):673-680.

520 Fischer FP, Schulz U, Schubert H, Knapp P, Schmöger M. 1997. Quantitative assessment of 521 grassland quality: acoustic determination of population sizes of orthopteran indicator $522 \quad$ species. Ecological Applications, 7(3):909-920.

523 Fung TK, Tan MK, Sivasothi N. 2018. Orthoptera in the scat content of the common palm 524 525

Gasc A, Gottesman BL, Francomano D, Jung J, Durham M, Mateljak J, Pijanowski BC. 2018. 529 Soundscapes reveal disturbance impacts: Biophonic response to wildfire in the Sonoran 530 Desert Sky Islands. Landscape Ecology. 33(8):1399-1415. 
531 Gerhardt HC. 1991. Female mate choice in treefrogs: static and dynamic acoustic criteria.

$532 \quad$ Animal Behaviour. 42(4):615-635.

533 Gehrt SD, Chelsvig JE. 2004. Species- specific patterns of bat activity in an urban landscape.

534 Ecological Applications. 14(2):625-635.

535 Gil D, Brumm H. 2014. Acoustic communication in the urban environment: patterns,

536 mechanisms, and potential consequences of avian song adjustments. Avian urban ecology.

537 Oxford University Press, Oxford. 69-83.

538 Google Earth Pro. 2020. Google Earth Pro 7.3.3.7699 (64-bit). Google, California.

539 Gorochov AV. 1983. Grylloidea (Orthoptera) of the Soviet Far East. In Bodrova; Soboleva \&

540 Meshcheryakov [Ed.]. Systematics and Ecological-Faunistic Review of the Various Orders $541 \quad$ of Insecta of the Far East. 1-154.

542 Gorochov AV, Tan MK. 2012. New crickets of the subfamilies Phaloriinae and Pteroplistinae

543 (Orthoptera: Gryllidae) from Singapore. Zootaxa. 3525:18-34.

544 Grimm NB, Faeth SH, Golubiewski NE, Redman CL, Wu J, Bai X, et al. 2008. Global

$545 \quad$ change and the ecology of cities. Science. 319:756-760.

546 Gurule-Small GA, Tinghitella RM. 2018. Developmental experience with anthropogenic

547 noise hinders adult mate location in an acoustically signalling invertebrate. Biology

$548 \quad$ Letters. 14(2):20170714.

549 Hicks R. 2020. In pictures: Nature is thriving in locked-down Singapore-is it time to rethink

550 the city in a garden? Eco-Business. URL: https://www.eco-business.com/news/in-

551 pictures-nature-is-thriving-in-locked-down-singapore-is-it-time-to-rethink-the-city-in-a-

552 garden/ [20 May 2020]

$553 \mathrm{Hu}$ Y, Cardoso GC. 2010. Which birds adjust the frequency of vocalisations in urban noise?

554 Animal Behaviour. 79(4):863-867. 
555 Irvine KN, Devine-Wright P, Payne SR, Fuller RA, Painter B, Gaston KJ. 2009. Green space, $556 \quad$ soundscape and urban sustainability: an interdisciplinary, empirical study. Local $557 \quad$ Environment. 14(2):155-172.

558 Lowry H, Lill A, Wong BB. 2011. Tolerance of auditory disturbance by an avian urban $559 \quad$ adapter, the noisy miner. Ethology. 117(6):490-497.

560 Martin SD, Gray DA, Cade WH. 2000. Fine-scale temperature effects on cricket calling song. $561 \quad$ Canadian Journal of Zoology. 78(5):706-712.

562 Matsuda N, Tanaka K, Watari Y, Shintani Y, Goto SG, Nisimura T, Izumi Y, Numat H.

563 2018. Northward expansion of the bivoltine life cycle of the cricket over the last four 564 decades. Global Change Biology. 24(12):5622-5628.

565 McKinney ML. 2006. Urbanisation as a major cause of biotic homogenisation. Biological 566 Conservation. 127:247-260.

567 Meteorological Service Centre. Undated. Historical Daily Records. Available from:

568 http://www.weather.gov.sg/climate-historical-daily/ Accessed 10 June 2020.

569 Møller AP. 2009. Successful city dwellers: a comparative study of the ecological

570 characteristics of urban birds in the Western Palearctic. Oecologia. 159(4):849-858.

571 Montealegre-Z F, Morris GK, Mason AC. 2006. Generation of extreme ultrasonics in 572 rainforest katydids. J Exp Biol. 209:4923-4937.

573 Morley EL, Jones G, Radford AN. 2014. The importance of invertebrates when considering 574 the impacts of anthropogenic noise. Proceedings of the Royal Society B: Biological $575 \quad$ Sciences. 281(1776):20132683

576 Nakagawa S, Schielzeth H. 2010. Repeatability for Gaussian and non- Gaussian data: a 577 practical guide for biologists. Biological Reviews. 85(4):935-956. 
578 Nandi D, Balakrishnan R. 2013. Call intensity is a repeatable and dominant acoustic feature 579 determining male call attractiveness in a field cricket. Animal Behaviour. 86(5):1003$580 \quad 1012$.

581 Nemeth E, Brumm H. 2010. Birds and anthropogenic noise: are urban songs adaptive?. The $582 \quad$ American Naturalist. 176(4):465-475.

583 Newbold T, Hudson LN, Hill SLL, Contu S, Lysenko I, Senior RA, et al. 2015. Global 584 effects of land use on local terrestrial biodiversity. Nature. 520:45-50.

585 Newman P. 2014. Biophilic urbanism: a case study on Singapore. Australian Planner. $586 \quad 51(1): 47-65$.

587 Oksanen J, Blanchet FG, Kindt R, Legendre P, Minchin PR, O’Hara RB, ... Wagner H. 2015. 588 vegan: Community Ecology Package. R package version 2.0-10.

589 Orci KM, Petróczki K, Barta Z. 2016. Instantaneous song modification in response to 590 fluctuating traffic noise in the tree cricket Oecanthus pellucens. Animal Behaviour. $591 \quad 112: 187-194$.

592 Otte D. 1992. Evolution of cricket songs. J. Orthoptera Res. 1:25-49.

593 Otte, D. 2006. Gryllodes sigillatus (Walker) is a valid species distinct from Gryllodes 594 supplicans (Walker). Transactions of the American Entomological Society. 132(1):223595227

596 Payne CJ, Jessop TS, Guay PJ, Johnstone M, Feore M, Mulder RA. 2012. Population, 597 behavioural and physiological responses of an urban population of black swans to an $598 \quad$ intense annual noise event. PloS one. 7(9).

599 Popov AV, Shuvalov VF. 1977. Phonotactic behaviour of crickets. Journal of Comparative $600 \quad$ Physiology. 119(1):111-126.

601 R Development Core Team. 2018. R: A language and environment for statistical computing. 602 R Foundation for Statistical Computing, Vienna, Austria. 
603 Ragge DR, Reynolds WJ. 1998. The Songs of the Grasshoppers and Crickets of Western 604 Europe. Colchester, UK: Harley Books.

605 Raimbault M, Dubois D. 2005. Urban soundscapes: Experiences and knowledge. Cities. $606 \quad 22(5): 339-350$.

607 Sala OE. 2000. Global biodiversity scenarios for the year 2100. Science. 287:1770-1774.

608 Schuster AC, Carl T, Foerster K. 2017. Repeatability and consistency of individual behaviour 609 in juvenile and adult Eurasian harvest mice. The Science of Nature. 104(3-4):1-14.

610 Simmons LW, Zuk M. 1992. Variability in call structure and pairing success of male field 611 crickets, Gryllus bimaculatus: the effects of age, size and parasite load. Animal Behaviour. 612 44(6):1145-1152.

613 Skånberg A, Öhrström E. 2002. Adverse health effects in relation to urban residential 614 soundscapes. Journal of Sound and Vibration. 250(1):151-155.

615 Slabbekoorn H. 2013. Songs of the city: noise-dependent spectral plasticity in the acoustic 616 phenotype of urban birds. Animal Behaviour. 85(5):1089-1099.

617 Smith DA, Gehrt SD. 2010. Bat response to woodland restoration within urban forest 618 fragments. Restoration Ecology. 18(6):914-923.

619 Smith RL, Thomas W. 1988. Southwestern distribution and habitat ecology of Gryllodes 620 supplicans. Bulletin of the ESA. 34(4):186-191.

621 Stockfelt T. 1991. Sound as an existential necessity. Journal of Sound and Vibration. 151(3): $622 \quad 367-370$.

623 Stoffel MA, Nakagawa S, Schielzeth H. 2017. rptR: repeatability estimation and variance 624 decomposition by generalised linear mixed- effects models. Methods in Ecology and $625 \quad$ Evolution. 8:1639-1644. 
626 Sueur J. 2002. Cicada acoustic communication: potential sound partitioning in a multispecies 627 community from Mexico (Hemiptera: Cicadomorpha: Cicadidae). Biological Journal of 628 the Linnean Society. 75(3):379-394.

629 Sueur J, Aubin T, Simonis C. 2008. Seewave, a free modular tool for sound analysis and $630 \quad$ synthesis. Bioacoustics. 18(2):213-226.

631 Tan MK. 2010. Orthoptera of the vacant lots in Bedok South. Nature in Singapore. 3:69-81. 632

Tan MK. 2011. The Copiphorini (Orthoptera: Tettigoniidae: Conocephalinae) in Singapore. $633 \quad$ Nature in Singapore. 4:31-42.

634 Tan MK. 2012. Orthoptera of the exhumed Bidadari cemetery, Singapore. Nature in $635 \quad$ Singapore. 5:343-350.

636 Tan MK. 2017. Orthoptera in the Bukit Timah and Central Catchment Nature Reserves (Part 637 2): Suborder Ensifera. $2^{\text {nd }}$ Edition. Lee Kong Chian Natural History Museum, National $638 \quad$ University of Singapore, Singapore. 101 pages. Uploaded 16 June 2017.

639 Tan MK. 2013. Orthoptera in the mangroves of Singapore. Nature in Singapore. 6:289-230.

640 Tan MK, Artchawakom T, Wahab RA, Lee C-Y, Belabut DM, Tan HTW. 2017b.

641 Overlooked flower visiting Orthoptera in Southeast Asia. Journal of Orthoptera Research. $642 \quad 26(2): 143-153$.

643 Tan MK, Montealegre-Z F, Wahab RA, Lee C-Y, Belabut DM, Japir R. Chung AYC. 2019

644 Ultrasonic songs and stridulum anatomy of Asiophlugis crystal predatory katydids

645 (Tettigonioidea: Meconematinae: Phlugidini). Bioacoustics.

646 Tan MK, Robillard T. 2014. A new species of Cardiodactylus (Orthoptera: Grylloidea:

647 Eneopterinae) from Singapore. Zootaxa. 3764(3):364-376.

648 Tan MK, Tan HTW. 2017. Between florivory and herbivory: Inefficacy of decision-making 649 by generalist floriphilic katydids. Ecological Entomology. 42(2):137-144. 
650 Tan MK, Yeo H, Hwang WS. 2017a. Ground dwelling pygmy grasshoppers (Orthoptera:

651 Tetrigidae) in Southeast Asia tropical freshwater swamp forest prefer wet microhabitats.

652 Journal of Orthoptera Research. 26(1):73-80.

653 Tan MK, Yong CYH, Ahmad Sah HH, Ingrisch S, Wahab RA, Johns PM. 2018. Inferring

654 species boundaries using acoustic and morphological data in the ground cricket genus

655 Gymnogryllus (Orthoptera: Grylloidea: Gryllinae). Systematics and Biodiversity. $656 \quad 16(8): 731-742$.

657 Walker TJ. 1962. Factors responsible for intraspecific variation in the calling songs of $658 \quad$ crickets. Evolution. 16(4):407-428.

659 Weissman DB, Rentz DCF. 1977. Feral house crickets Acheta domesticus (L.) (Orthoptera:

660 Gryllidae) in southern California. Entomological News. 88(9/10):246-248.

661 Wilson SJ, Bayne EM. 2019. Songbird community response to regeneration of reclaimed 662 wellsites in the boreal forest of Alberta. Journal of Ecoacoustics, 3, I4B2LF.

663

664 
666

667 Table 1. Number of individuals recorded (n ID) and echemes ( $\mathrm{N}$ echemes) analysed for each 668 species.

\begin{tabular}{|c|c|c|c|}
\hline Family: Subfamily & Taxon names & n ID & $\mathbf{N}$ echemes \\
\hline Gryllidae: Gryllinae & Gryllodes sigillatus (Walker, 1869) & 9 & 64 \\
\hline Gryllidae: Gryllinae & Gryllus bimaculatus De Geer, 1773 & 1 & 11 \\
\hline Gryllidae: Gryllinae & Teleogryllus c.f. mitratus (Burmeister, 1838) & 1 & 4 \\
\hline Gryllidae: Gryllinae & Gryllinae & 4 & 40 \\
\hline Gryllidae: Gryllinae & ?Mitius sp. & 1 & 4 \\
\hline Trigonidiidae: & Polionemobius taprobanensis (Walker, & 20 & 169 \\
\hline Nemobiinae & 1869) & & \\
\hline Trigonidiidae: & Pteronemobius sp. & 2 & 22 \\
\hline \multicolumn{4}{|l|}{ Nemobiinae } \\
\hline Trigonidiidae: & Nemobiinae & 1 & 6 \\
\hline \multicolumn{4}{|l|}{ Nemobiinae } \\
\hline Trigonidiidae: & Trigonidiinae & 1 & 17 \\
\hline \multicolumn{4}{|l|}{ Trigonidiinae } \\
\hline Tettigoniidae: & Euconocephalus sp. & 2 & 18 \\
\hline Conocephalinae & & & \\
\hline
\end{tabular}

669

670

671 
672 Table 2. Results from models with delta $<2.0$ examining how environmental conditions

673 predicts syllable duration and fundamental frequency. ID refers to individual cricket identity

$\begin{array}{lllll}\text { Model with } & \text { AICc } & \text { Weight } & \mathrm{R}^{2}{ }_{\mathrm{M}} & \mathrm{R}^{2} \mathrm{C} \\ \text { delta }<0.20 & & & & \end{array}$

\begin{tabular}{lccccc}
\hline $\begin{array}{l}\text { Syllable duration } \\
\text { Polionemobius }\end{array}$ & $\sim 1+(1 \mid \mathrm{ID})$ & -418.8 & 0.90 & 0.00 & 0.45 \\
taprobanensis & $\sim 1+(1 \mid \mathrm{ID})$ & -198.3 & 0.95 & 0.00 & 0.59 \\
Gryllodes sigillatus & $\sim 1+(1 \mid \mathrm{ID})$ & -1017.9 & 0.97 & 0.00 & 0.97 \\
\hline Fundamental frequency & & & & & \\
Polionemobius & $\sim 1+(1 \mid \mathrm{ID})$ & -443.5 & 0.97 & 0.00 & 0.96 \\
taprobanensis & & & & & \\
\hline Gryllodes sigillatus & & & & & \\
\hline
\end{tabular}

674

675

676 Figure captions:

677

678 Figure 1. Map of Singapore (a) with the arrow indicating the location of the study site. The 679 inset photographs (b-d) illustrate the grass verges that were sampled at the time of sampling 680 (b) and during the day (c, d).

681

682 Figure 2. Individual-based rarefaction curve showing the cumulative number of species 683 recorded.

684

685 Figure 3. Oscillograms of the crickets and bush-cricket calls. 686 
687 Figure 4. Power spectra of the crickets and bush-cricket calls based on a single echeme using

688 Hamming window of window length 512.

689

690 Figure 5. PCoA plot showing the partitioning in the call properties of the cricket species. The 691 ellipses represent the standard deviations for each species.

692

693 Figure 6. Spectrogram showing the partitioning in the call properties (both time and

694 frequency domains) between Polionemobius taprobanensis (a), Gryllodes sigillatus (b) and 695 Pteronemobius (c). 